\title{
Influence of powder morphology and microstructure on the cold spray and mechanical properties of Ti6Al4V coatings
}

\author{
Venkata Naga Vamsi Munagala ${ }^{\mathrm{a}}$, Valary Akinyi ${ }^{\mathrm{a}}$, Phuong Vo ${ }^{\mathrm{b}}$, Richard R. Chromik ${ }^{\mathrm{a}^{*}}$ \\ ${ }^{\mathrm{a}} \mathrm{McGill}$ University, Department of Mining and Materials Engineering, 3610 University \\ Street, Montreal, QC H3A 0C5, Canada \\ bational Research Council Canada, 75 de Mortagne Blvd., Boucherville, QC J4B 6Y4, \\ Canada
}

\begin{abstract}
The powder microstructure and morphology has significant influence on the cold sprayability of Ti6Al4V coatings. Here, we compare the cold sprayability and properties of coatings obtained from Ti6Al4V powders of spherical morphology (SM) manufactured using plasma gas atomization and irregular morphology (IM) manufactured using the Armstrong process. Coatings deposited using IM powders had negligible porosity and better properties compared to coatings deposited using SM powders due to higher particle impact velocities, porous surface morphology and more deformable microstructure. To evaluate the cohesive strength, multi-scale indentation was performed and hardness loss parameter was calculated. Coatings deposited using SM powders exhibited poor cohesive strength compared to coatings deposited using IM powders. Images of the residual indents showed de-bonding and sliding of adjacent splats in the coatings deposited using SM powders irrespective of the load. Coatings deposited using IM powders showed no evidence of de-bonding at low loads. At high loads, splat de-bonding was observed resulting in hardness loss despite negligible porosity. Thus, while the powders from Armstrong process lead to a significant improvement in sprayability and coating properties, further optimization of powder and cold spray (CS) process will be required as well as consideration of post-annealing treatments to obtain acceptable cohesive strength.
\end{abstract}

Keywords: Armstrong process; Ti6A14V; Titanium alloys; Cold spray; Nanoindentation; Particle morphology 


\section{Introduction}

Ti alloy Ti6Al4V is widely used in aerospace, automobile and biomedical applications due to its high strength-to-weight ratio, bio-compatibility and corrosion resistance. Various processing techniques like plasma spraying, selective laser melting and electron beam melting have been previously used to deposit Ti and its alloys as coatings.(Ref 1-4) These techniques involve high working temperatures resulting in phase transformations, tensile residual stresses and high temperature oxidation.(Ref 1,3$)$

To overcome these challenges, a low temperature process named as cold spray or cold gas dynamic spraying is under evaluation to deposit coatings at temperatures well below the melting point of the material.(Ref 5) CS is a novel thermal spray process that involves solid-state deposition of feedstock powders. In this process, powder particles are accelerated to supersonic velocities by a pre-heated gas stream (propellant gas) using a de Laval type nozzle and are subsequently impacted onto prepared substrates. The strain rates achieved in this process are typically in the range of $10^{3}$ $/ \mathrm{s}-10^{9} / \mathrm{s}$. (Ref 6,7) As the particles impact on the substrates at such a high strain rates, they deform plastically resulting in coating buildup.(Ref 8$)$ Since the CS process uses the kinetic energy of the particles for the successful deposition of the coatings, the deleterious effects of high temperature oxidation, phase transformations and/or tensile residual stresses in the coatings can be minimized or eliminated.(Ref 9) Despite numerous advantages, there are some limitations and challenges in depositing coatings using the CS process. To deposit coatings using the CS process, a material should exhibit plastic deformation and possess some amount of ductility.(Ref 9,10) Hence, brittle materials like ceramics cannot be directly deposited using the CS process and are co-deposited using a ductile matrix.(Ref 9) Furthermore, cold sprayed coatings exhibit poor tensile properties due to severe strain hardening experienced by the particles upon impact at high stain rates and require heat treatment to gain ductility.(Ref $10-12)$

Using CS, a wide range of metals, alloys and composite coatings can be deposited onto different substrates; however, deposition of high yield strength materials like Ti6Al4V are challenging.(Ref 9,12-14) Prior works illustrate that the high yield strength of Ti6Al4V makes it extremely difficult to CS and the resultant coatings had high porosity.(Ref 12,13,15-17) Vo et al. deposited Ti6Al4V coatings using Nitrogen $\left(\mathrm{N}_{2}\right)$ and Helium $(\mathrm{He})$ as propellant gas.(Ref 12) They found that the coatings deposited using $\mathrm{N}_{2}$ as propellant gas had significant porosity whereas coatings deposited 
using He were dense. This was mainly due to the high velocities achieved by the particles with $\mathrm{He}$ that resulted in higher particle deformation. Tan et al. studied the effect of gun traverse speed on porosity and adhesion of Ti6AlV coatings.(Ref 18) Their results illustrate that lowering the gun traverse speed from $500 \mathrm{~mm} / \mathrm{s}$ to $100 \mathrm{~mm} / \mathrm{s}$ reduced the porosity in the coatings from $3.2 \%$ to 0.5 $\%$ due to greater interaction of the hot gas stream with the substrate. However, reducing the gun traverse speed resulted in a significant reduction in coating adhesion strength between the substrate and coating. Khun et al. deposited Ti6Al4V coatings on Ti6Al4V substrates and found that the coatings deposited using $\mathrm{N}_{2}$ had higher porosity when compared to coatings deposited using He.(Ref 15) They also found that the dense Ti6Al4V coatings deposited using He gas exhibited superior hardness, wear and corrosion resistance compared to the coatings deposited using $\mathrm{N}_{2}$. Their results indicated that the coating porosity had significant influence on the mechanical properties and performance of the coatings. Bhattiprolu et al. used He to deposit Ti6AlV coatings from feedstock powders of different microstructures.(Ref 19) They found that coatings deposited using hydride de-hydride powders of equiaxed $\alpha$ microstructure had comparable adhesion strength and porosity to the coatings deposited using atomized powders with martensitic $\alpha^{\prime}$ microstructure. Dense Ti coatings with high DE were deposited by MacDonald et al. using IM powders manufactured using Armstrong process.(Ref 20) They proposed that the unique morphology of the powder particles allows them to breakdown and flatten on each other upon impact resulting in dense coatings; however, with poor cohesive strength.

Single splats of Ti6Al4V onto various substrates were deposited by Vidaller et al. and cavitation tests were performed to understand the bond strength between the splats and the substrate.(Ref 21) Their results show that a higher hardness of the substrate compared to the spray material leads to more deformation of the splats, resulting in greater adhesion strength. Goldbaum et al. deposited single splats of Ti6Al4V to understand the effect of process conditions on adhesion strength.(Ref 14) Based on the results of splats adhesion tests, they found that the adhesion strength of the splats was higher when sprayed at higher velocities using He. Higher particle velocities lead to higher strain rates when particle impacts onto the substrate; thus resulting in higher deformation. To reduce porosity in Ti6Al4V coatings, Luo et al., used an in-situ shot peening process by mixing steel balls with the metal powder in the initial feedstock.(Ref 22) Peening action by these steel balls during the CS process reduced the porosity in the final coatings. An initial mixture varying from $0 \%$ to $70 \mathrm{vol} . \%$ of steel balls in the initial feedstock resulted in porosity reduction from 13.7 
$\%$ to $0.7 \%$. Based on the literature, it can be concluded that deposition of pure Ti6Al4V coatings with low porosity when sprayed using $\mathrm{N}_{2}$ as propellant gas remains challenging. Furthermore, most of the works discussed in the above literature offered very limited or absolutely no data regarding the DE of the coatings. Thus, there is a need for a study to understand and deposit dense Ti6Al4V coatings with special emphasis on the effect of feedstock powder microstructure and characteristics on the final coating properties.

The aim of our work is to understand the influence of initial microstructure and powder morphology on the CS of Ti6Al4V coatings. In the present study, two different morphologies of powders, i.e. spherical and irregular, have been cold sprayed onto mild steel substrates. The two powders are microstructurally and morphologically distinct and were manufactured using different processing techniques. Powders were systematically characterized in terms of phases, surface structure and cross-section microstructures and were related to the coating porosity, hardness and DE. Electron channel contrast imaging (ECCI) was used to characterize the feedstock powder cross-sections and splats in the coatings to link the initial and final cold sprayed microstructures. Hardness loss parameter was calculated by performing indentation at different loads and length scales to examine the cohesive strength between the splats. Microstructure characterization and coating properties, were used to understand the structure-process-property relationship. 


\section{Experimental procedure}

\section{Feedstock powder characterization and cold spraying}

Ti6Al4V coatings were cold sprayed onto mild steel substrates of dimensions $75 \times 75 \times 3 \mathrm{~mm}^{3}$ using a PCS 800 system (Plasma Giken, Japan) with $\mathrm{N}_{2}$ as propellant gas. Commercially pure (CP) Ti6Al4V powders (Grade 5) of spherical morphology (SM) (AP\&C, Canada) (size range: $15 \mu \mathrm{m}$ - $45 \mu \mathrm{m}$ ) and irregular morphology (IM) (Cristal Metals, USA) (size range: 0 - $45 \mu \mathrm{m}$ ) with average particle diameters of $31 \mu \mathrm{m}$ and $38 \mu \mathrm{m}$ respectively, were used as feedstock. The size distributions of the powders were evaluated using a laser scattering particle size distribution analyzer (LA-920, Horiba, Japan) and are shown in Fig. 1. The SM powders were manufactured by plasma gas atomization process and the IM powders were manufactured by Armstrong process.(Ref 23,24) The flowability and apparent density of the powders were measured as per Metal Powders Industries Federation (MPIF) standards 3 and 28 using Hall-flow and Carney flowmeter. An average of 3 measurements was taken to determine the flowability and apparent density of the powders. The specific surface area and the pore volume were determined using Brunauer-EmmettTeller (BET) analysis i.e. gas absorption technique (TriStar 3000, Micromeritics Instrument, USA), with $\mathrm{N}_{2}$ as absorbent. X-ray diffraction analysis for phase determination was done on feedstock powders using an X-ray diffractometer (Bruker, Germany) with $\mathrm{Cu}-\mathrm{K} \alpha$ as a source operated at a power of $40 \mathrm{kV}$ and $40 \mathrm{~mA}$. Subsequently, phase matching was performed on the generated diffractograms using the standard intensity peaks corresponding to their respective Bragg angles taken from JCPDS data card no. 00-044-1294 ( $\alpha$ - Ti) and 00-044-1288 ( $\beta$ - Ti).

Prior to CS deposition the mild steel substrates were de-greased with acetone and grit blasted using alumina to enhance the bonding between the coating and substrate. The gas pressure and temperature to deposit all the coatings were fixed at $4 \mathrm{MPa}$ and $800^{\circ} \mathrm{C}$, respectively. The standoff distance between the nozzle and the substrate was kept $40 \mathrm{~mm}$ and the gun traverse speed was 0.2 $\mathrm{m} / \mathrm{s}$. The in-flight particle velocities were measured using a time of flight particle diagnosis system (Coldspraymeter, Tecnar Automation, Canada). The DE of the coatings deposited was calculated by taking a ratio of the weight of the powder deposited to the weight of the powder sprayed. The weight of the powder deposited was calculated by taking the difference between the weight of the sample before and after coating deposition, whereas the weight of the powder sprayed was 
determined by taking a ratio of the product of the powder feed rate and total distance travelled by the gun on the sample to the gun traverse speed.
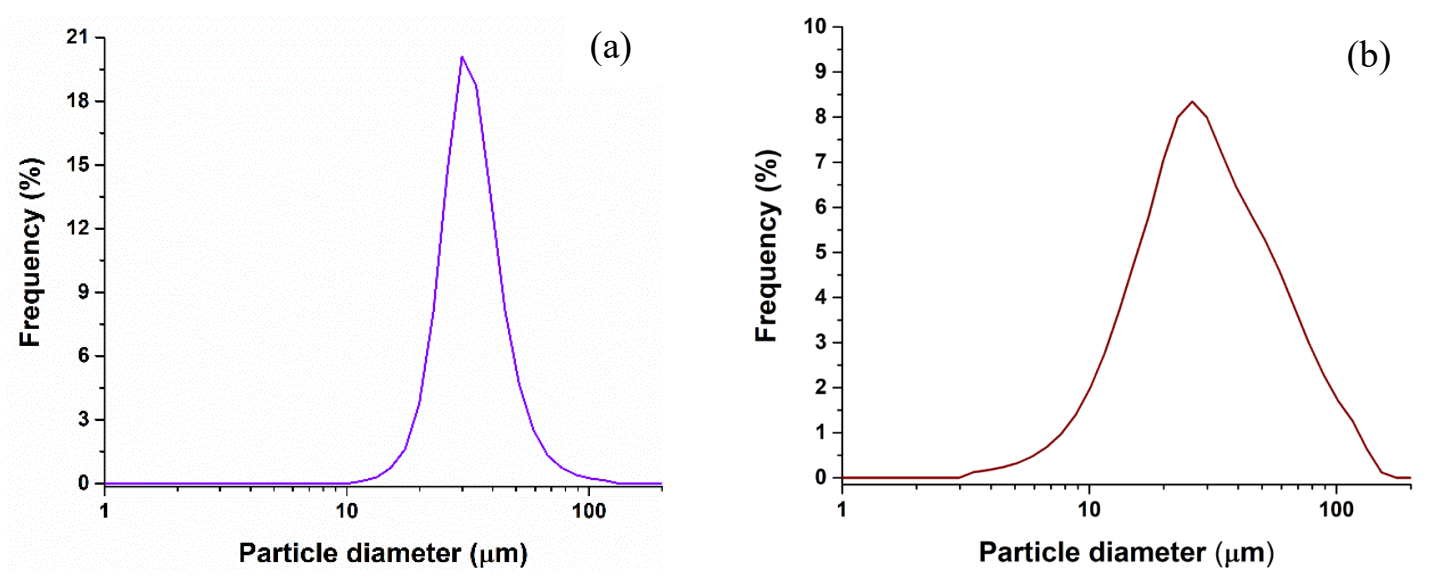

Fig. 1. Ti6Al4V powder size distribution of (a) SM and (b) IM

\section{Coating characterization}

Coatings were cut perpendicular to the gun traverse direction, cold mounted and polished down to $0.05 \mu \mathrm{m}$ colloidal silica suspension. These polished samples were observed under a scanning electron microscope (SEM) (SU3500, Hitachi, Japan) equipped with a back scattered electron (BSE) detector. BSE images were taken at different locations within the coating cross-section at magnifications ranging between $60 \mathrm{x}-80 \mathrm{x}$ and porosity in the coatings was determined by measuring the pixels associated with the difference in contrast, from the BSE images using ImageJ software. At least 15 images were analyzed to calculate average porosity. To relate the microstructure of the initial feedstock powders and coatings, ECCI was performed on powder and coating cross-section. ECCI on the cross-sections was done using a cold field emission SEM (SU8230, Hitachi, Japan) fitted with a photodiode BSE detector. ECCI is a powerful technique to visualize crystal defects like grain boundaries, dislocations within a spatial resolution of $\sim 1 \mathrm{~nm}$. It is based on the orientations of the back scattered electrons that are emitted from a polycrystalline material due to different angular orientations of the crystals.(Ref 7,25) 


\section{Coating hardness}

Nanoindentation was performed on the coatings using a Triboindentor (Hysitron Incorporated, USA) with a diamond Berkovich tip. Indentation was done on the coating cross-section and on a bulk CP-Ti6Al4V plate (polished in a similar manner as that of coating cross-sections) at loads ranging between 1 to $20 \mathrm{mN}$ with loading and unloading segments of $5 \mathrm{~s}$ and holding time of $2 \mathrm{~s}$ to study indentation size effect. The Ti6Al4V plate had an equiaxed microstructure as shown in Fig. 2 with $\alpha$ and $\beta$ phase mixtures. Nanoindentation tests were performed at the centre of the coatings away from the free surface and substrate-coating interface. The nanohardness was calculated using the load-displacement curves as described by Oliver and Pharr.(Ref 26) Microhardness tests were done using a Vickers diamond indenter (Clark Microhardness tester, USA) on the polished cross-sections of the coatings and the Ti6Al4V plate at different loads within a range of $25 \mathrm{~g}-500 \mathrm{~g}$ and holding time of $15 \mathrm{~s}$. An average of fifteen indents was done to calculate the final hardness at each load. Images of the residual indents were captured at 500x magnification using an optical microscope attached to the hardness testing machine. Vickers hardness (VH) was calculated by dividing the applied load by the surface area of the indent. $V H\left(\mathrm{~kg} / \mathrm{mm}^{2}\right)$ and was converted into $H_{\text {micro }}(\mathrm{GPa})$ using a conversion from surface area to projected area using Eq. 1. (Ref 27)

$$
H_{\text {micro }}(G P a)=\frac{V H \times 9.8 \mathrm{~m} / \mathrm{s}^{2}}{1000 \times \sin 68^{\circ}}
$$

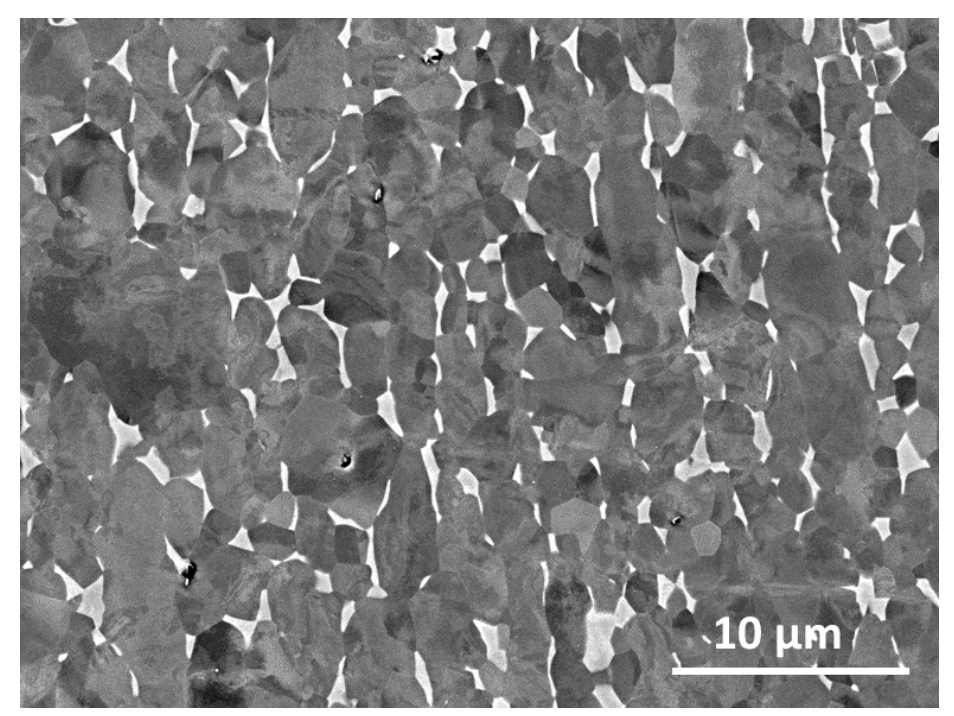

Fig. 2. ECCI showing cross-section of Ti6Al4V 


\section{Results}

\section{Characterization of the feedstock powders}

SM powders exhibited a cellular surface morphology (see Fig. 3a-b), which is a feature expected from the plasma gas atomization process.(Ref 24) ECCI of the cross-section of the SM Ti6Al4V powders revealed the presence of martensitic laths (Fig. 3c), which were formed due to rapid directional solidification resulting in martensitic bcc- $\beta$ to hcp- $\alpha$ phase transformations.(Ref 28$) \mathrm{A}$ close examination of the martensitic laths indicated the presence of dislocation twins inside laths, as seen in Fig. 4 (shown by white circle). Martensitic structures $\left(\alpha^{\prime}\right)$ of Ti6A14V alloy possess crystal defects and are sites for high dislocations densities such as stacking faults and dislocation twins when compared to pure $\alpha$-phase.(Ref 29) In contrast, the IM powders were manufactured by the Armstrong process and showed a different surface morphology along with the presence of porosity throughout the particles (see Fig. 3d-e). Polished cross-sections of the IM powders showed an equiaxed alpha microstructure with a grainsize $\sim 3.2 \mu \mathrm{m}$ (Fig. 3f). XRD of SM and IM powders revealed stable $\alpha$-phase of Ti and there was no measurable $\beta$-Ti phase observed (due to its low volume fraction) as shown in Fig. 5.

The results of BET analysis are summarized in Table 1. The specific surface area of SM powders is less than IM powders. The flowability and apparent density of the powders are also presented in Table 1. SM powders had excellent flowability whereas the IM powders did not flow through the Hall-flow meter. The apparent density of IM Ti6Al4V powders was significantly lower than that of SM powders mainly due to its porous structure. 
Table 1 Feedstock powder characteristics

\begin{tabular}{ccccc}
\hline Powder & $\begin{array}{c}\text { Specific } \\
\text { surface area } \\
\left(\mathrm{m}^{2} / \mathrm{g}\right)\end{array}$ & $\begin{array}{c}\text { Total pore } \\
\text { volume of the } \\
\text { pores }\left(\mathrm{cm}^{3} / \mathrm{g}\right)\end{array}$ & $\begin{array}{c}\text { Hall } \\
\text { flowability } \\
(\mathrm{s} / 50 \mathrm{~g})\end{array}$ & $\begin{array}{c}\text { Apparent } \\
\text { density } \\
\left(\mathrm{g} / \mathrm{cm}^{3}\right)\end{array}$ \\
\hline Spherical Ti6A14V & 0.046 & --- & $40.5 \pm 0.7$ & 2.49 \\
Irregular Ti6A14V & 0.301 & $59.1 \times 10^{-5}$ & No flow & 0.86 \\
\hline
\end{tabular}
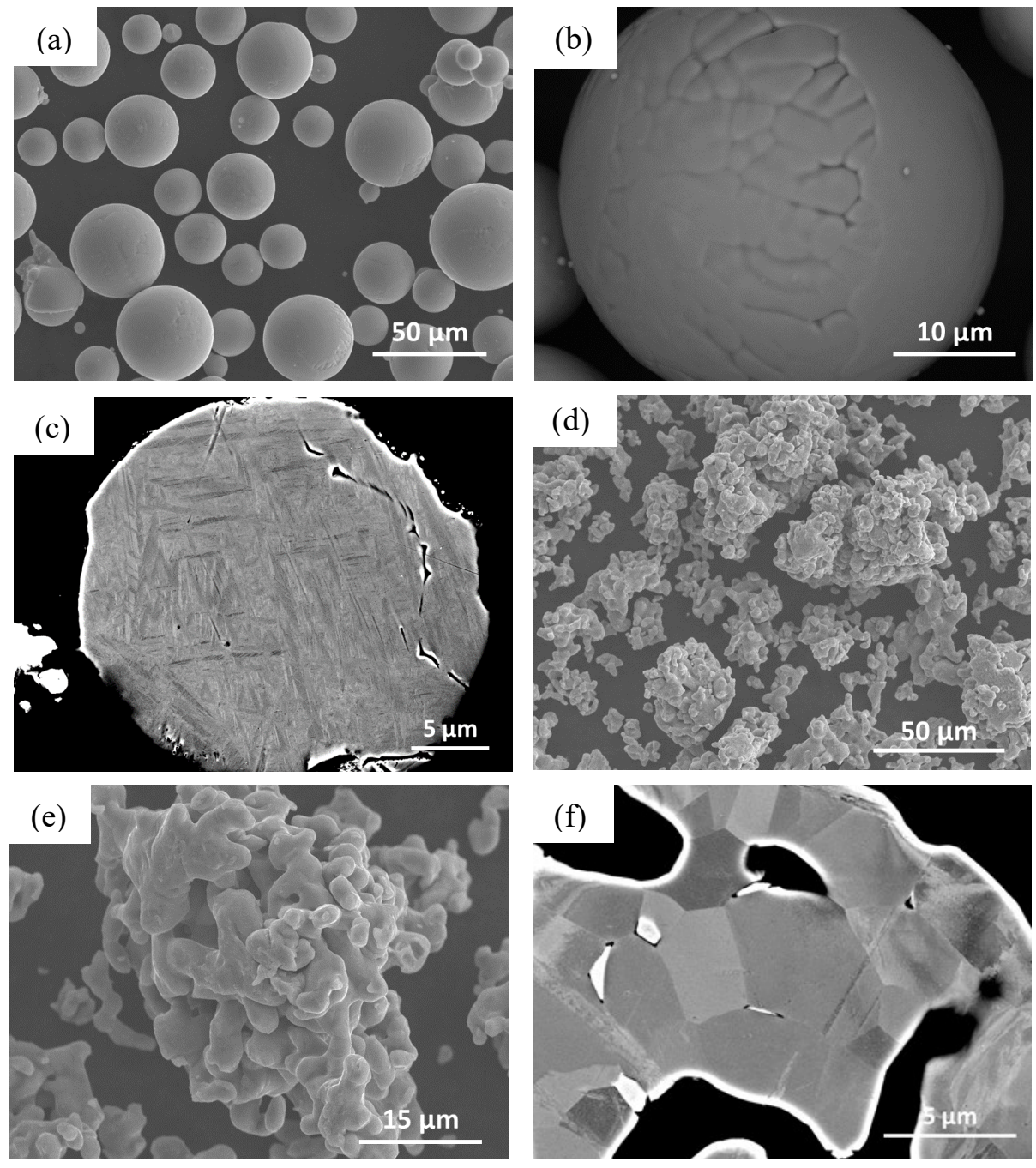

Fig. 3. Surface morphology of (a) \& (b) SM powders (low and high magnification); (d) \& (e) IM powders ; ECCI of cross section of (c) SM (f) IM powders 


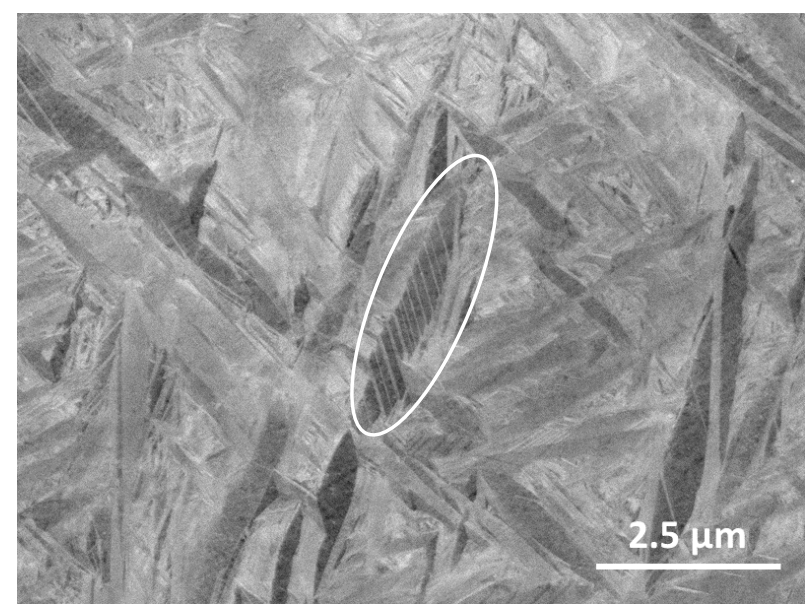

Fig. 4. ECCI of the powder cross-section of spherical Ti6Al4V powder showing dislocation twins inside the martensitic laths (features inside the white oval).

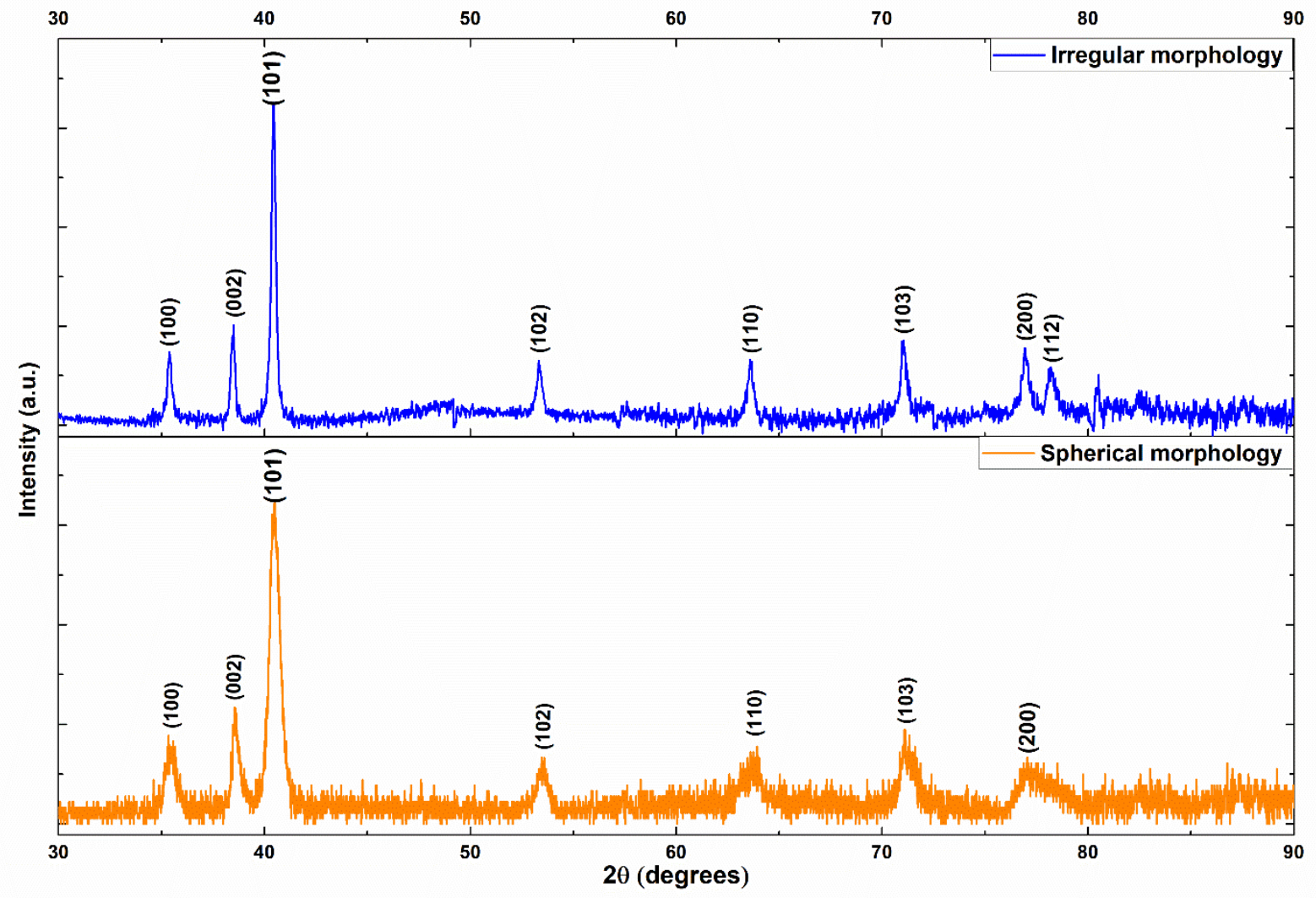

Fig. 5. XRD diffractograms of IM and SM Ti6A14V powders 


\section{Characterization of the cold sprayed coatings}

\section{Top surface morphology of the coatings}

Figure 6 shows the top surface morphology of pure Ti6Al4V coatings cold sprayed using SM and IM feedstock powders. Ti6Al4V coatings deposited using SM powders showed evidence of adiabatic shear instabilities (ASI), by evidence of material jetting (see Fig. 6a). Also, most of the SM feedstock particles retained their initial morphology leading to significant gaps between deposited particles. For coatings deposited using IM powders, no conclusive evidence of ASI was found (Fig. 6b), which may simply be due to the complicated structure of these powders making direct observation difficult. Nevertheless, the coatings deposited using IM exhibited a denser microstructure with less evidence of gaps between the particles. Top surface porosity for coatings deposited using IM powders was mainly due to the porosity in their initial feedstock particles (Fig. 3d-e).
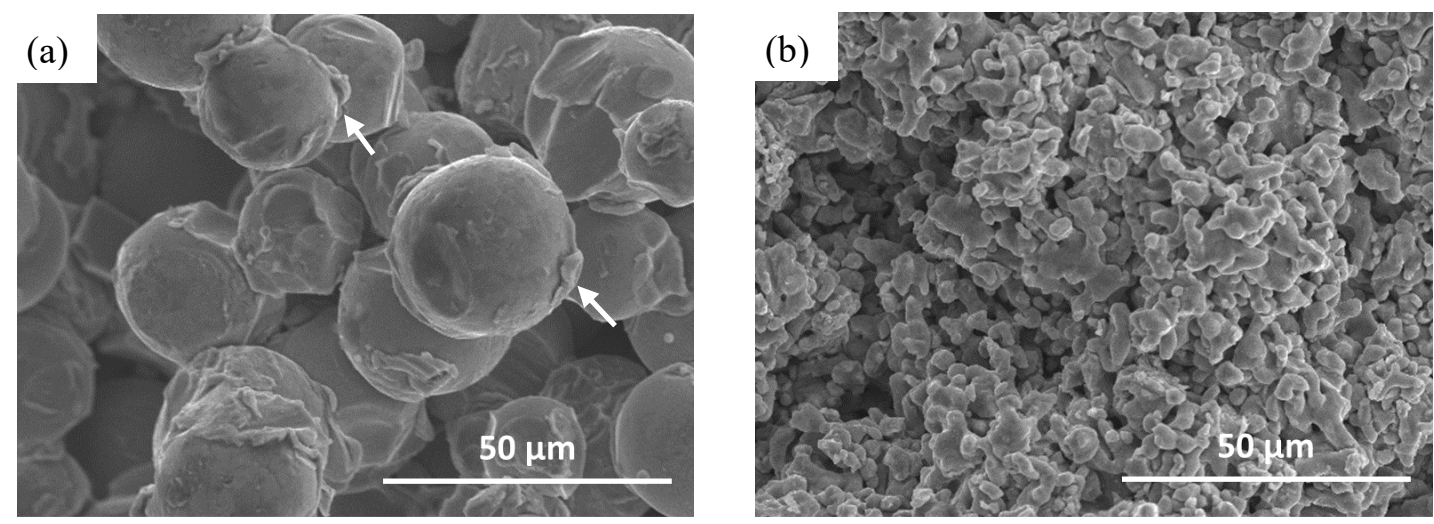

Fig. 6. Top surface morphology of Ti6Al4V coatings deposited using (a) SM powders (b) IM powders White arrows in (a) indicate locations with evidence of material jetting 


\section{Deposition efficiency and particle velocity}

Table 2 shows the DE of Ti6Al4V coatings deposited using SM and IM powders of similar size range. The DE of coatings deposited using IM powders was marginally greater than those deposited using SM powders due to the higher impact velocity for the similar spray conditions (i.e. gas pressure and temperature). The measured in-flight particle velocities, shown in Table 2 demonstrated the higher velocity of irregular particles, which is due to the higher drag force acting on the particles with IM. The drag force acting on an in-flight particle can be expressed as illustrated in Eq. 2: (Ref 30)

$$
D=\frac{1}{2} \rho V_{r e l}^{2} A_{p} C_{D}
$$

where $D$ is the drag force acting on the particle, $\rho$ is the mass density of the propellant gas, $V_{r e l}$ is the relative velocity between the gas stream and the particle, $A_{p}$ is the projected surface area of the particle and $C_{D}$ is the drag coefficient. From Eq. 2. the drag force acting on the particle is proportional to the drag coefficient. For a particle in a fluid environment, the drag coefficient is a sum of frictional drag and form drag. Frictional drag coefficient of the spherical and non-spherical particles is same whereas the form drag on the IM particle is higher than spherical particle due pressure variation around the particle. (Ref 30) This form drag depends on the morphology of the object or particle present in the fluid environment. For an irregular shaped particle, the boundary layer separation occurs at an early stage due to variation in pressure gradient on the two opposite surfaces. Hence, it experiences greater amount of drag force when compared to a spherical particle in a gas stream.

Table 2 Ti6Al4V coatings characteristics and particle velocity measurements

\begin{tabular}{cccccc}
\hline $\begin{array}{c}\text { Ti6Al4V coatings } \\
\text { deposited using }\end{array}$ & $\begin{array}{c}\text { Particle } \\
\text { velocity } \\
(\mathrm{m} / \mathrm{s})\end{array}$ & Porosity $(\%)$ & $\begin{array}{c}\text { Coating } \\
\text { hardness } \\
\left(\mathrm{HV}_{0.5}\right)\end{array}$ & DE (\%) & $\begin{array}{c}\text { Coating } \\
\text { thickness } \\
(\mathrm{mm})\end{array}$ \\
\hline SM powders & $619 \pm 87$ & $13.0 \pm 2.0 \%$ & $174 \pm 44$ & $85 \%$ & $2.24 \pm 0.03$ \\
IM powders & $732 \pm 88$ & $0.3 \pm 0.1 \%$ & $197 \pm 15$ & $92 \%$ & $1.35 \pm 0.01$ \\
\hline
\end{tabular}




\section{Coating porosity}

The porosity of Ti6A14V coatings deposited using IM powders was significantly less compared to SM powders as seen in Table 2 . The high porosity of Ti6Al4V coatings deposited using SM powders is mainly due to the limited deformation of the particles, as observed from the crosssection (Fig. 7a), and top view (Fig. 6a) SEM images of the coatings. Coatings deposited using irregular Ti6Al4V powders exhibited a dense microstructure with no evidence of particles retaining their initial morphology (Fig. 7b).
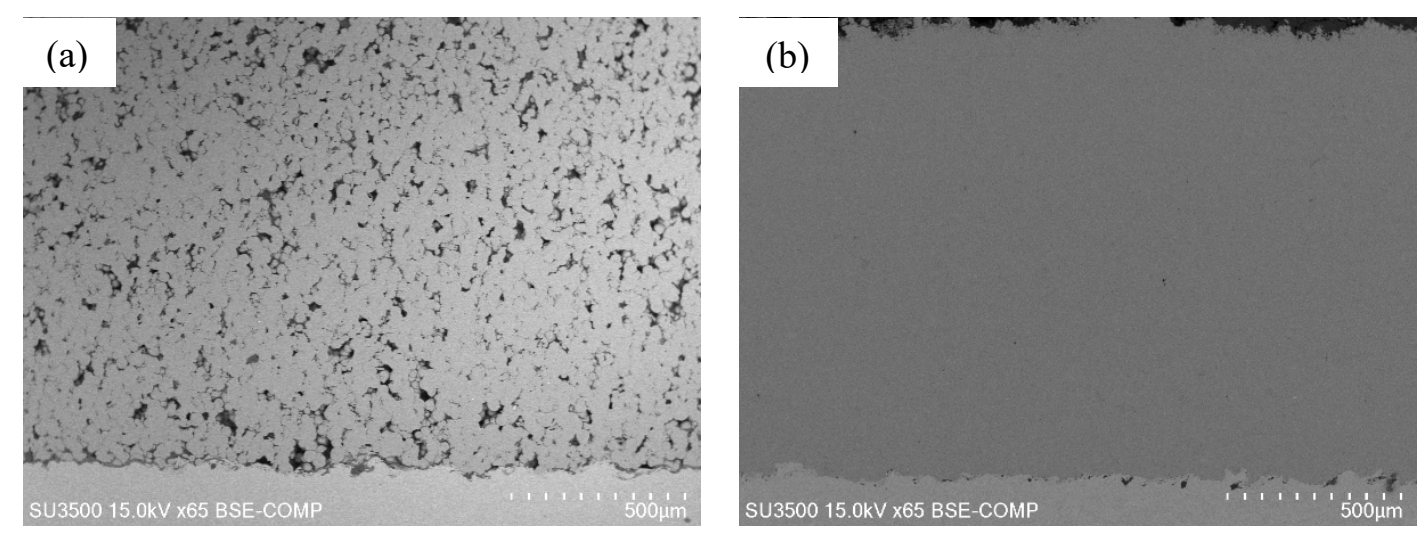

Fig. 7. Cross-section images of Ti6Al4V coatings deposited using (a) SM powders (b) IM powders

\section{Microstructure of the coatings}

To understand the microstructure, ECCI was performed on the Ti6Al4V coatings deposited using SM and IM powders. Figure 8a shows an ECCI of the Ti6Al4V coating deposited using SM powders. Most of the region inside the splat showed a martensitic lath structure similar to that of the initial feedstock microstructure as previously shown in Fig. 3c. However, near the splat boundary nanograins were observed (see Fig. 8a-b). This indicates that recrystallization had taken place close to the particle boundary during the splat impact. Nanograins were observed up to $\sim 8$ $\mu \mathrm{m}$ from the splat boundary, beyond which the initial martensitic lath-like microstructure of the feedstock powder was retained. Recrystallization near the splat boundaries is a result of the high strain rate and rise in localized temperature during particle impact at supersonic velocities onto the substrate or previously deposited layer. Since the rise in temperature is localized near the contact zone, recrystallization was primarily observed at splat boundaries. ECCI of the Ti6Al4V coatings deposited using IM powders illustrates that the powder particles underwent significant amount of 
deformation as seen in Fig. 8c. Recrystallization was observed at the splat boundaries and these were followed by heavily deformed grains as we move inside the splats. This can be seen in Fig. $8 \mathrm{c}-\mathrm{d}$. The recrystallized region predominantly consisted of nanograins of size $<15 \mathrm{~nm}$, as observed in Fig. 8d. Furthermore, it is worth observing that in the case of coatings deposited using SM powders initial microstructure was seen away from the splat boundaries whereas in case of coatings deposited using IM powders the initial microstructure of the feedstock particles was limitedly seen.
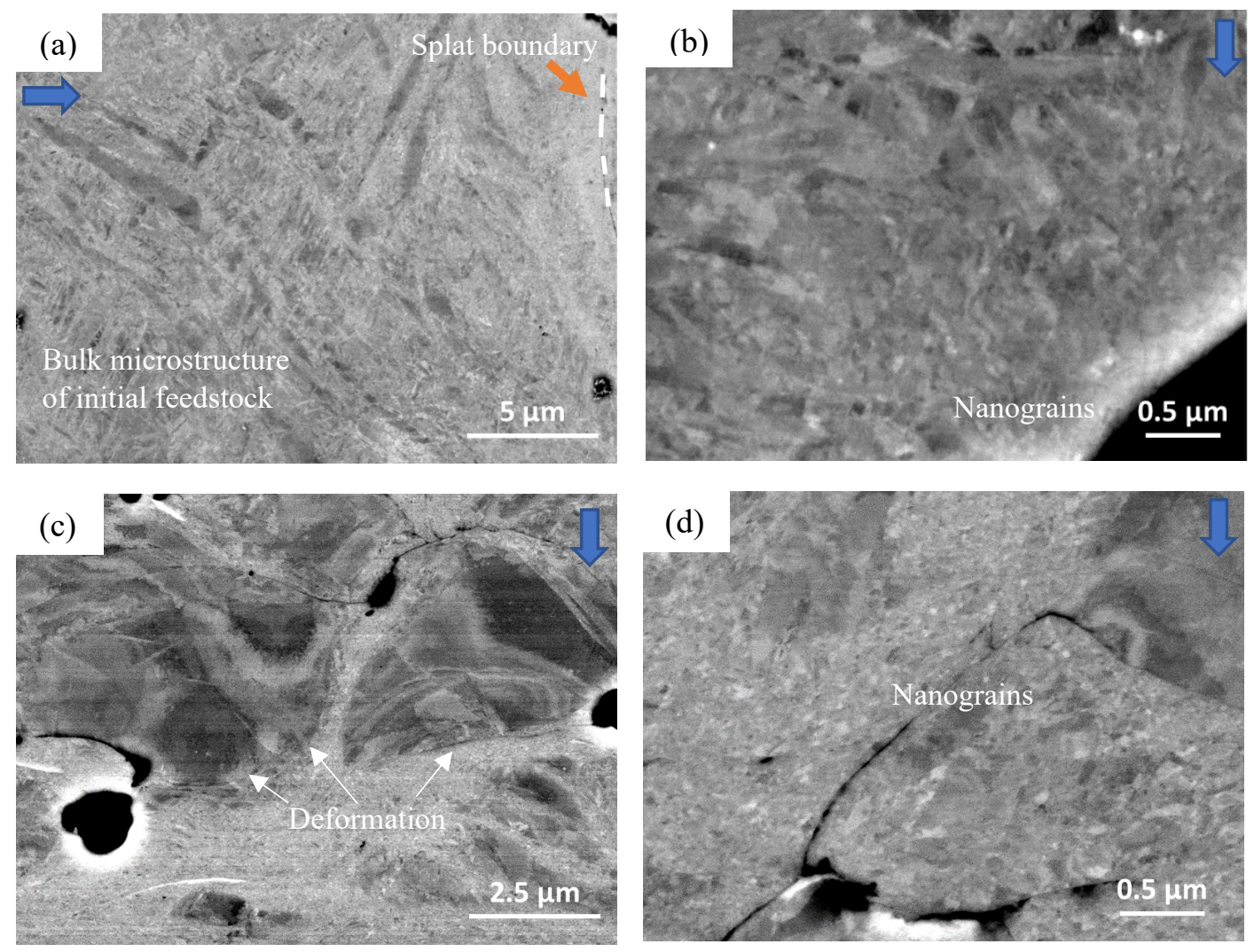

Fig. 8. ECCI of Ti6Al4V coating cross-sections deposited using (a) SM powder (c) IM powder and (b) \& (d) high magnification images at the splat boundaries respectively; Blue arrow - indicates spray direction. 


\section{Indentation size effect on the coatings and hardness loss parameter Nanohardness test results}

Nanoindentation was performed on the coating cross-section and on the bulk Ti6Al4V plate at different loads ranging between $1 \mathrm{mN}$ to $20 \mathrm{mN}$. With increase in indentation depth there was a general trend of decrease in hardness in both the coatings and bulk Ti6Al4V plate. The square of nanohardness as a function of inverse of indentation depth for the bulk Ti6A14V plate and coatings is shown in Fig. 9a-c. This data was fit to Nix-Gao model (as per Eq. 3) which illustrates that the indentation size effects can be related to the geometrically necessary dislocations.(Ref 31) This model is based on law of strain gradient plasticity, and the indentation depth and hardness in this model are related using Eq. 3.

$$
\frac{H}{H_{O}}=\sqrt{1+\frac{h^{*}}{h}}
$$

In the above equation $\mathrm{H}$ is the nanohardness, $\mathrm{H}_{\mathrm{o}}$ is the hardness of the material at infinite indentation depth, $\mathrm{h}^{*}$ is a characteristic length scale and $\mathrm{h}$ is the indentation depth. 

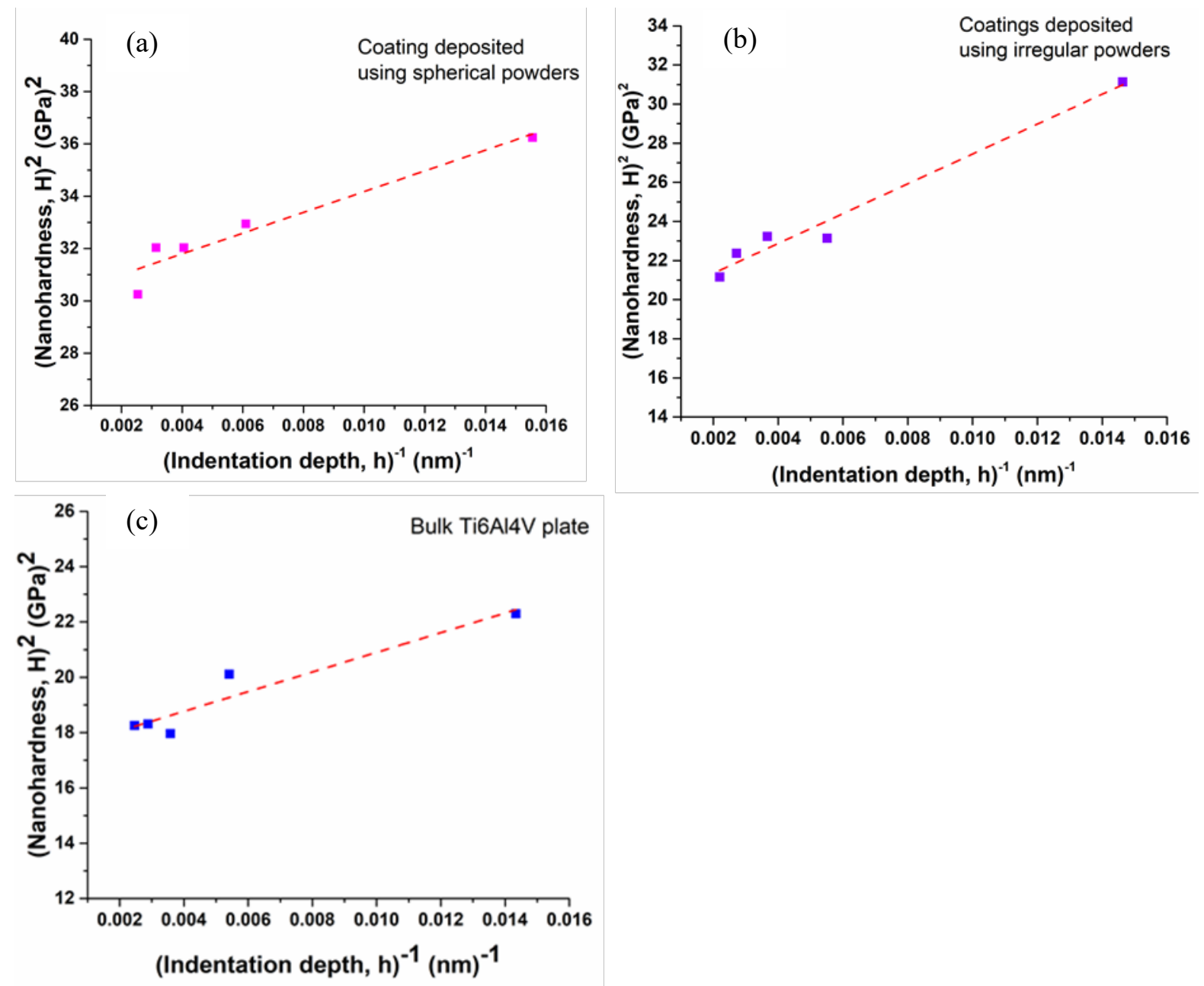

Fig. 9. Variation of square of hardness with inverse of indentation depth plotted according to Nix Gao model for (a) coatings deposited using SM powders (b) coatings deposited using IM powders and (c) bulk Ti6Al4V plate

The results of the regression fit of nanohardness to the indentation depth data as per Eq. 3. for the coatings deposited using SM and IM powders are shown in Table 3.

Table 3 Strain gradient plasticity parameters of bulk Ti6A14V plate and coatings

\begin{tabular}{ccc}
\hline Sample & $\mathrm{H}_{\mathrm{o}}(\mathrm{GPa})$ & $\mathrm{h}^{*}(\mathrm{~nm})$ \\
\hline Ti6A14V coatings deposited using SM powders & $5.49 \pm 0.05$ & $13.15 \pm 2.15$ \\
Ti6A14V coatings deposited using IM powders & $4.45 \pm 0.01$ & $38.54 \pm 3.53$ \\
Bulk Ti6Al4V plate & $4.17 \pm 0.04$ & $20.43 \pm 3.62$ \\
\hline
\end{tabular}


In Table 3, the value of $H_{o}$ represents the "true hardness" of the material independent of the load or depth of indentation where the hardness is influenced only by statistically stored dislocations. The true hardness of the bulk Ti6Al4V plate is lower than that of the cold sprayed coatings. This could due to the strain hardening and grain refinement in the powder particles upon impact at high strain rates during CS process. Furthermore, the true hardness of the Ti6Al4V coatings deposited using SM powders was higher than that of IM powder. This can be attributed to the initial microstructure of the two feedstock powders in which the presence of martensitic laths in SM powders would have contributed to the higher hardness.

In Eq. 3 the $\mathrm{h}^{*}$ represents the characteristic length that depends on the shape of the indenter, shear modulus and $\mathrm{H}_{\mathrm{o}}$ value. The lower value of $\mathrm{h}^{*}$ for coatings deposited using SM powders is mainly due to its plastic deformation resistant acicular microstructure. The values of $\mathrm{h}^{*}$ obtained here for the coatings deposited using IM powders closely match with the value of $42 \mathrm{~nm}$ reported by Sen et al. for Ti6A14V alloy of equiaxed microstructure.(Ref 32) Also, the crystal anisotropy in the case of Ti and its alloys influences the hardness values which in turn affects the $h^{*}$.(Ref 33 ) However, despite these differences the $\mathrm{h}^{*}$ of bulk Ti6Al4V plate is lower that that of coating deposited using SM powders which can be due to their differences in microstructures.

\section{Microhardness test results}

Microhardness tests were performed at different loads within a range of $25 \mathrm{~g}-500 \mathrm{~g}$ on the bulk Ti6Al4V plate and coatings and the hardness as a function of indentation depth is shown in Fig. 10. There is a decrement in microhardness with an increase in indentation depth; however, as the indentation depth increased beyond $\sim 4 \mu \mathrm{m}$, the hardness values remained constant. This trend was observed in both the coatings and bulk Ti6Al4V plate. Furthermore, the variation in the microhardness of the bulk Ti6A14V with indentation depth was lower when compared to CS coatings. The diagonals of the residual Vickers indents were found to be approximately between $30 \mu \mathrm{m}-75 \mu \mathrm{m}$ at the loads where the hardness approached a constant value. At such large indentation sizes, there will be a definite interaction of the indenter with the splat boundaries and porosity present in the coatings. This indicates that microhardness tests reveal the indentation size effect in a different manner compared to nanoindentation, with greater interaction with macroscopic defects like splat boundaries and porosity. 


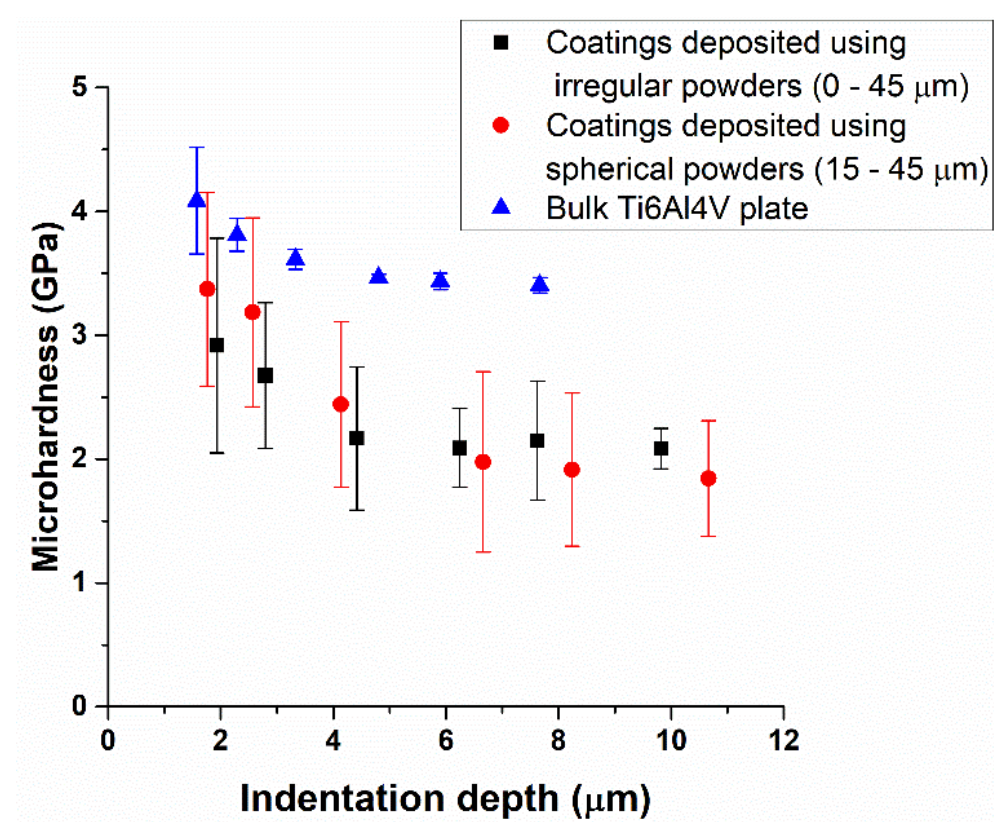

Fig. 10. Microhardness of bulk Ti6Al4V plate and coatings

\section{Calculation of hardness loss parameter}

The hardness loss for the coatings is calculated using Eq. 4. as proposed previously by Goldbaum et al. (Ref 27)

$$
\operatorname{Hardness} \operatorname{loss}(\%)=\frac{H_{O}(G P a)-H_{P l a t e a u}(G P a)}{H_{O}(G P a)} \times 100
$$

In Eq. 4., $\mathrm{H}_{\mathrm{o}}$ represents the true hardness of the material derived from the Nix-Gao fit (Eq. 3) to nanoindentation data and $\mathrm{H}_{\text {plateau }}$ is the plateau hardness of the material, which is taken as an average microhardness from the three highest loads. Hardness loss for the bulk Ti6A14V plate and coatings deposited using the two feedstock powders are shown in Table 4.

Table 4 Hardness loss

\begin{tabular}{ccc}
\hline Sample & Hplateau $_{\text {(GPa })}$ & Hardness loss (\%) \\
\hline Ti6A14V coatings deposited using SM powders & $1.91 \pm 0.054$ & $65.20 \%$ \\
Ti6Al4V coatings deposited using IM powders & $2.11 \pm 0.029$ & $52.58 \%$ \\
Bulk Ti6Al4V plate & $3.43 \pm 0.025$ & $17.74 \%$ \\
\hline
\end{tabular}


The hardness loss values of CS coatings were higher than that of bulk Ti6Al4V plate. Furthermore, the hardness loss was higher in the case of Ti6Al4V coatings deposited using SM powders when compared to coatings deposited using IM powders.

To understand the reason behind the high hardness loss, despite low porosity levels (in the case of coatings deposited using IM powders), the residual indents after microhardness tests were examined under an optical microscope. Fig. 11 shows the images of the residual indents at the two extreme loads, i.e. $25 \mathrm{~g}$ and $500 \mathrm{~g}$ for the bulk Ti6Al4V plate and coatings. The indents on bulk Ti6Al4V plate show a perfect diamond shape of the Vickers indenter at both the loads as seen in Fig. 11a-b. The minor loss in hardness obtained could be due to deviations from a perfect shape of the diamond indent at low loads as shown in Fig. 11a. These minor deviations are mainly due to the crystal anisotropy in Ti and its alloys.(Ref 33,34$)$

Micrographs of residual indents on cold sprayed coatings showed multiple phenomena that were not observed for the bulk Ti6Al4V plate. In the case of coatings deposited using SM powders, an interaction of the indenter with the porous regions was found at both low and high loads. Debonding of the splats in these coatings was observed in almost all cases (Fig. 11c-d \& g). Additionally, for some tests, there was sliding of an adjacent splat onto the residual indent due to poor bonding between the splats (Fig. 11d). While tests like this were not used for measurements of hardness, they provided additional evidence of the poor bonding in the coatings from SM powders. As discussed previously, the SM powders had an acicular microstructure that resists plastic deformation of the particles upon impact; thereby resulting in porosity and improper bonding between the splats. Thus, the presence of porosity and de-bonding of splats during microhardness tests led to a low plateau hardness of these coatings and resulted in high hardness loss.

In the case of coatings deposited using IM powders, there was minimum interaction of the indenter with porosity at low loads as seen in Fig. 11e. At higher loads, the interaction of the indenter with porosity was comparatively higher and de-bonding was observed specifically in these regions, as shown in Fig. 11h. Even in dense regions de-bonding of splats was found when indentation was performed at higher loads indicating poor cohesive strength between the splats (Fig. 11f). Poor bonding between the splats reduces the cohesive strength and results in de-bonding. However, the sliding of adjacent splats was not observed for these coatings. De-bonding of the splats during 
indentation reduces the load bearing capacity thereby reducing the plateau hardness of the coatings. This explains the low hardness of coatings deposited using IM powders despite low porosity and subsequently the higher hardness loss values. 

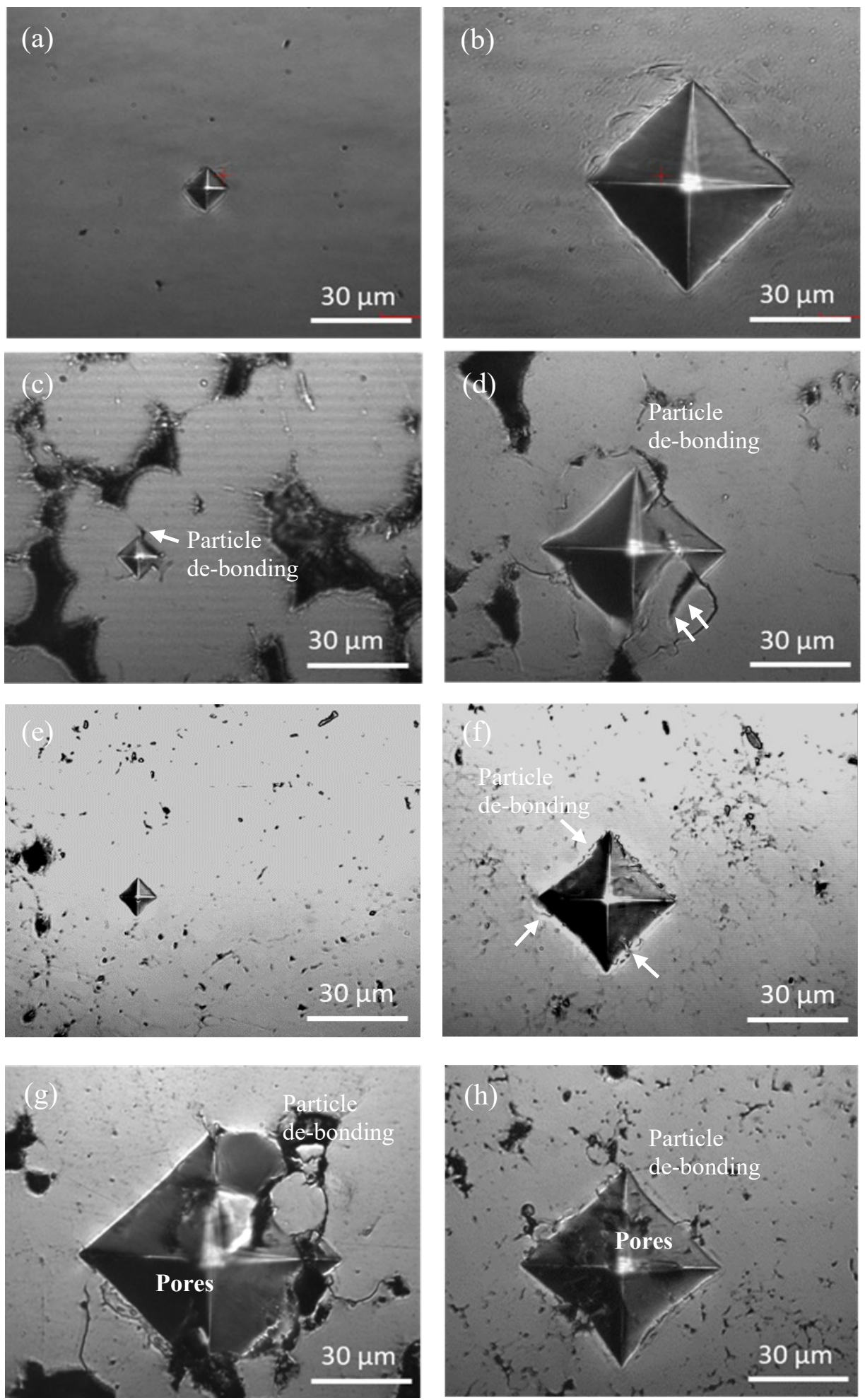

Fig. 11. Optical micrographs of the residual indents on (a) \& (b) bulk Ti6Al4V plate at 25 $\mathrm{g}$ and $500 \mathrm{~g}$ load (c) \& (d) coatings deposited using SM powders at $25 \mathrm{~g}$ and $500 \mathrm{~g}$ load (e) \& (f) coatings deposited using IM powders at $25 \mathrm{~g}$ and $500 \mathrm{~g}$ load (g) \& (h) porous region in the coatings deposited using SM and IM powders at $500 \mathrm{~g}$ load 


\section{Discussion}

\section{General characteristics of the feedstock powders}

Feedstock powders play an important role in the CS process since the successful deposition, microstructure and final properties of the coatings depend largely on powder initial properties. Some researchers have indicated that engineering of powders for better cold sprayability is one of the prime needs to develop and improve applications of the CS process.(Ref 19,20) One alloy system that has immediate applications for CS is Ti6Al4V, but the inherent high yield strength and melting point has made for mostly poor cold sprayability and inability to obtain a near fully dense deposit with acceptable mechanical properties. Past researchers have cold sprayed Ti6Al4V with SM powders, but attained limited success to obtain dense coatings without post heat treatments.(Ref $12,16,17,35)$ The most recent development for Ti and Ti6Al4V is the preparation of powders using the Armstrong process. Only a few reports have been made on this powder for CS, but some improvements are reported.(Ref 20) McDonald et al. deposited dense coatings of Ti using the Armstrong powders at low gas pressures and temperatures. They concluded that that unique morphology of the particles allows to deposit Ti coatings well below its critical velocity. The most common powder morphology for CS is spherical, and here we have compared spherical powders to irregular powders made by the Armstrong process.

The primary limitation in using IM powders is due to their poor flowability, which was true from their Hall flowability number. However, this did not have any significant effect on the coating characteristics like DE, porosity etc. SM powders have a good Hall flowability. The flow characteristics of the powders depend on various parameters like size, shape, interparticle friction and weight of the bulk powder.(Ref 36) The poor flowability of the IM powders can be attributed to their high interparticle friction and low apparent density. This impedes the free movement of one particle over another thereby resulting in poor flowability.(Ref 36) Another concern is that industries require no nozzle clogging or pulsating effects at the inlet of the nozzle that can often result from poor flowability and lead to waviness in the coatings.(Ref 37) However, despite their poor flowability, no pulsating effects, nozzle clogging or waviness in the final coatings was observed for the IM powders. In a high pressure CS system, pressurized $\mathrm{N}_{2}$ gas passing through the feeder to transport the feedstock powders to the inlet of the nozzle may help counter the potential for poor flowability of the IM powders. Furthermore, while many irregular powders have 
been shown to be unacceptable for CS, the unique morphology of the IM powders from the Armstrong process, with high specific surface area and complicated surface porosity may have allowed the pressurized gas to purge though them and improve their flowability in a forced gas environment.

\section{Coatings characteristics}

As discussed previously, high particle velocities and specific surface area enhance the particle deformation as the particle impacts the substrate. Additionally, the powder particle microstructure also plays an important role in determining the deformation of the incoming feedstock particles. Studies carried out by Murr et al. illustrated that Ti6A14V alloy with acicular or martensitic lath like structure exhibits higher yield strength than lamellar and equiaxed microstructures.(Ref 4) Since in CS process, the coatings are developed by the plastic deformation of the powder particles, high yield strength materials need higher velocities to deposit coatings.(Ref 13) The SM had fine laths of $\alpha$-phase leading to limited plastic deformation upon impact and a retention of most of the spherical shape. Powders of this type result in high porosity (seen in Fig. 7a), which has been observed by previous researchers.(Ref 12,16) In the case of IM powders, the microstructure was a more deformable equiaxed $\alpha$-phase. This led to more deformation upon impact of the particles resulting in dense coatings with negligible porosity. Furthermore, IM powders had porosity (Fig. 3e) and also possess higher specific surface area compared to SM powders. These two aspects help for greater interaction between the particle and the hot gas stream thereby resulting in higher heat transfer.(Ref 38) An increase in particle temperature would cause thermal softening and lead to even more improvement of deformability of the IM powders.

In the past, researchers tried to engineer the powders and reduce porosity in Ti6Al4V coatings. Aydin et al. mixed Ti and Ti6Al4V and found that a mixture of $10 \mathrm{vol} \%$ Ti to Ti6Al4V reduced the porosity from $6.7 \%$ to $1.5 \%$; there was no effect with further increase in Ti\%.(Ref 16) Lou et al. mixed different volume fractions of steel balls with $\mathrm{Ti}$ and Ti6Al4V powders to reduce porosity.(Ref 22) However, the resultant coatings had steel balls entrapped in the final coatings. Khun et al., Bhattiprolu et al. and Vo et al. suggested that dense coatings of Ti6Al4V deposited using SM powders can only be achieved by spraying with He as propellant gas.(Ref $12,15,19)$ A summary of the above literature suggests that innovative techniques have been used to reduce the porosity in Ti6Al4V coatings; however, each technique had its own limitations or increased the 
deposition costs. In present work, IM powders with deformable and porous structure were used to deposit Ti6Al4V coatings. In view of the industrial requirements and cost economics, coatings were deposited using $\mathrm{N}_{2}$ as propellant gas and no post treatments were performed. The Ti6Al4V coatings deposited using these powders were extremely dense with porosity $<1 \%$.

Apart from deformable microstructure and high specific surface area other mechanisms may be acting as well for reduced porosity. Previously, Yin et al. and Lioma et al., found that porosity in the particles reduced particle rebounding and resulted in dense coatings.(Ref 39,40) Their results illustrated that the fracturing of the pores as the particles make an impact, resulted in cracking thus absorbing the particle kinetic energy and reduce the probability of rebounding. Gao et al. reported that the coatings deposited using powder particles with high and medium porosity were dense and thick when compared to coatings deposited using powders with low porosity. (Ref 41) They concluded that optimum porosity and deformability of particles help in depositing dense coatings with continuous buildup. While no observation of particle fragmentation was made in this work, the mechanism described by previous researchers may also be partly responsible for the low porosity of the IM coatings.

\section{Effect of powder morphology on coating microstructure}

Comparisons of the microstructure of the coatings to the initial powders were performed with ECCI on the coating cross-sections near to the splat interface. Most of the splat microstructure in coatings from SM powders resembled that the initial feedstock particles and recrystallization was observed only close to the splat interfaces. Martensitic laths observed in the initial powder were found away from the recrystallized region indicating very limited deformation at these positions. These observations are similar to those reported previously by Goldbaum et al. and Kim et al. for SM powders of CP-Ti. (Ref 7,42) Recrystallization was observed close to the splat interface or boundaries where primarily ASI, strain localization and rise in interfacial temperatures predominantly takes place during the particle impact.(Ref 42) Since the rise in temperature is concentrated very close to the interface and the bulk of the particle remains at lower temperatures, recrystallization was observed close to the splat boundaries. The limited regions of recrystallized grains inside the splats from SM powders are a further indication of the limited deformation that took place, which led to the higher porosity and poorer mechanical properties. 
ECCI of the splats in the coatings deposited using IM powders revealed a high degree of deformation with less evidence of initial feedstock microstructures. Nanograins were found along the splat interfaces similar to that of the coatings deposited using SM powders as well as highly deformed regions adjacent to them proceeding into the splat interior. The high degree of deformation in these coatings was because of the unique particle morphology, higher impact velocities, particle temperatures and the deformability of the initial powder microstructure. (Ref 20) Previously, Schmidt et al. illustrated that low yield strength and high particle temperatures result in lowering the critical velocity for deposition.(Ref 13) Furthermore, higher particle impact velocities result in an increase in strain rates, total strain and higher interfacial temperatures at splat boundaries, leading to greater amounts of deformation and recrystallized regions. Additionally, a larger specific surface area and presence of pores result in a higher rate of heat transfer, thereby increasing the particle temperature and heat retention within the particle. Since $\mathrm{Ti}$ and its alloys have higher heat capacity compared to other metals like $\mathrm{Zn}, \mathrm{Cu}, \mathrm{Pb}, \mathrm{Sn}$ etc., recrystallization and deformation are further enhanced by the temperature gradients across the particle interfaces, thus contributing to superior deformation.(Ref 13)

\section{Coating hardness and cohesive strength evaluated using multi-scale indentation}

At the scale of nanoindentation, coatings with SM powders showed higher hardness than those with IM powders. This is largely due to the retention of the martensitic lath microstructure of the SM powders, which is known to have high hardness. While the IM powders formed fine scale recrystallized microstructures, the hardness of these features and the deformed particle interiors remained lower than for coatings from SM powders. At the scale of microindentation testing, Ti6Al4V coatings deposited using IM powders exhibited higher hardness compared to coatings

deposited using SM powders. The improvement in the hardness can be attributed to lower porosity and better coating cohesion strength. As reported by Goldbaum et al. the two scales of indentation testing reveal distinctly different information on mechanical properties.(Ref 27) Nanoindentation helps for comparison of coating microstructure, while microindentation probes the effects of larger scale defects like porosity and splat boundaries.

The cohesive strength between the splats was examined through the hardness loss parameter.(Ref 27) A small hardness loss value indicates better inter-splat cohesive strength. Hardness loss was higher for CS coatings compared to bulk Ti6A14V plate. This result is similar to what Goldbaum 
et al. observed for CS coating deposited from spherical and irregular CP-Ti powders.(Ref 27) Generally, it is not possible with cold-sprayed Ti and its alloys to observe the same mechanical properties as their bulk counterparts. However, it should be noted that the hardness loss observed by Goldbaum et al. for CP-Ti at similar particle impact velocities to those obtained here was approximately $60 \%$ for both coatings deposited using spherical and irregular powders.(Ref 27) Here for Ti6Al4V, the hardness loss was around $65 \%$ and $53 \%$ for coatings deposited using SM and IM powders respectively. On one hand, this could be indicative of poor cohesive strength of the Ti6A14V deposited using spherical powders, which would be expected considering the lower deformability of the alloy compared to the pure material. However, it may also be due to the high mechanical properties of the alloy in general. Furthermore, the marginally lower hardness loss obtained here for the coatings deposited using IM powders compare to irregular CP-Ti coatings could be due to the differences in specific surface area and pours structure of the feedstock powders that would have led to better cohesiveness between the splats. To better explain comparisons between this work and the previous study, one must turn to the examination of residual indents. Most of the features of splat debonding and interactions with porosity were observed in both studies. The only major difference found was the large scale debonding found for the SM coatings. This is the most direct comparison to the previous work as the morphology of the powder is very similar to that used by Goldbaum et al. and we see an increase in hardness loss for SM Ti6Al4V compared to SM CP-Ti.(Ref 27) However, turning to the coatings from IM powders, the hardness loss was lower than previously observed for CP-Ti coatings and SM powders of Ti6Al4V sprayed here. More importantly, the features observed on residual indents were much less dramatic in terms of splat debonding. There was evidence of small scale debonding events but no large scale failures at splat interfaces. Thus, despite the high hardness loss of the coatings from IM powders, they exhibited relatively better features in terms of cohesive strength compared to both the SM powders sprayed here and the previous work of Goldbaum et al. (Ref 27) Similar evidence of de-bonding of splats in the case of dense Ti coatings (deposited using Armstrong powders) can be seen from the indent images reported by MacDonald et al. (Ref 20). They proposed that the unique morphology of the powders could have led to flattening of particles and subsequent coating buildup with low cohesive strength. Thus, the de-bonding of splats observed in the optical micrographs of the residual indents coincide with the low hardness values reported and support the high hardness loss in CS coatings when compared to bulk Ti6A14V plate. 
Hardness loss values can be a good indicator of coating tensile properties.(Ref 43) Coatings with dense microstructure and good cohesive strength between the splats exhibit better tensile properties. Low hardness loss indicates that the coatings possess better cohesive strength and in turn show better tensile properties.(Ref 43) This can be seen from the results reported by MacDonald et al. in which the as-sprayed Ti coatings using the Armstrong powders had shown de-bonding of splats and poor tensile properties.(Ref 20) SEM images of the fracture surfaces after the tensile tests showed almost no evidence of metallurgical bonding between the splats indicating their poor inter-splat bonding. However, subsequent heat treatment of the coatings resulted in improvement in cohesive strength resulting in better tensile properties.

The effectiveness of powders from the Armstrong process in terms of their cold sprayability and mechanical properties of coatings were evaluated and compared to coatings from SM powders. Overall, there are clear and significant benefits imparted by the IM powders obtained from the Armstrong process for cold spraying of Ti6Al4V. However, the resulting mechanical properties are poor. While the residual indent features of the coating from IM powders was somewhat improved with no large-scale failures along splat boundaries, the mechanical properties were still clearly deficient with the spray conditions used here. Options left for researchers seeking to obtain a high quality deposit of Ti6Al4V would be to include some sample heating during deposition, which has been shown to be effective in the past or to spray with Helium (He).(Ref 14,19) Spraying with He has clear benefits with much higher particle speeds, leading to fully dense coating with much better mechanical properties.(Ref 12,15) In fact, the hardness loss was zero for a deposit of CP-Ti with He spraying.(Ref 27) Others spraying with He have observed good mechanical properties as-deposited. However, engineers seeking applications for the Armstrong process IM powder must consider costs and sustainability. Spraying with He is not sustainable and costly. And including heating during spraying or post heat treatments is not cost friendly and may not always be practical. Thus, while this study has demonstrated significant promise for the Armstrong process IM powder, the need for other steps in manufacturing a mechanically robust deposit of Ti6Al4V by CS seem to still be required. Further research will be required to determine which steps are most effective and economically feasible. 


\section{Conclusions}

Ti6Al4V coatings have been cold sprayed using SM and IM powders. A detailed characterization was performed to understand the physical and microstructural properties of the feedstock powders and were related to the coating properties. Hardness loss through multi-scale indentation was determined to understand the cohesive strength between the splats. Based on the study following conclusions are drawn:

1. SM powders had a cellular surface structure and excellent flowability whereas IM powders had a porous structure with poor flowability. ECCI on the cross-section of the SM powders revealed a martensitic lath like structure whereas IM powders showed an equiaxed microstructure. The two different morphologies and microstructures have a significant influence on the properties of cold sprayed coatings.

2. Coatings deposited using IM powders had low porosity $(<1 \%)$, higher hardness and DE compared to the coatings deposited using SM powders. This was due to their higher particle velocity, specific surface area and more deformable microstructure compared to SM powders.

3. Multi-scale indentation was performed on the coatings and bulk Ti6Al4V plate to determine the hardness loss. Hardness loss was higher in cold sprayed coatings compared to the bulk Ti6A14V plate due to the presence of porosity and poor cohesive strength between the splats.

4. Coatings deposited using SM powders exhibited high hardness loss due to particle de-bonding and the presence of a significant amount of porosity. Residual indents showed the adjacent particle sliding over the indent in these coatings indicating poor inter-splat bonding contributing to high hardness loss.

5. Despite low porosity, coatings deposited using IM powders exhibited hardness loss but lower than their spherical counterparts. In these coatings, de-bonding of splats resulted in hardness loss and no adjacent particle sliding on the residual indent was observed.

\section{Acknowledgements}

The authors are thankful for the technical assistance from Jean-Francois Alarie, Dina Goldbaum and Maniya Aghasibeig. The authors gratefully acknowledge the contributions of Rene Cooper from Cristal Metals for providing the irregular Ti6Al4V powders. 


\section{References}

1. E. Brandl, F. Palm, V. Michailov, B. Viehweger, and C. Leyens, Mechanical Properties of Additive Manufactured Titanium (Ti-6Al-4V) Blocks Deposited by a Solid-State Laser and Wire, Mater. Des., Elsevier Ltd, 2011, 32(10), p 4665-4675.

2. E. Brandl, A. Schoberth, and C. Leyens, Morphology, Microstructure, and Hardness of Titanium (Ti-6Al-4V) Blocks Deposited by Wire-Feed Additive Layer Manufacturing (ALM), Mater. Sci. Eng. A, Elsevier B.V., 2012, 532, p 295-307.

3. J. Cizek, O. Kovarik, J. Siegl, K.A. Khor, and I. Dlouhy, Influence of Plasma and Cold Spray Deposited Ti Layers on High-Cycle Fatigue Properties of Ti6A14V Substrates, Surf. Coatings Technol., Elsevier B.V., 2013, 217, p 23-33.

4. L.E. Murr, S.A. Quinones, S.M. Gaytan, M.I. Lopez, A. Rodela, E.Y. Martinez, D.H. Hernandez, E. Martinez, F. Medina, and R.B. Wicker, Microstructure and Mechanical Behavior of Ti-6Al-4V Produced by Rapid-Layer Manufacturing, for Biomedical Applications, J. Mech. Behav. Biomed. Mater., Elsevier Ltd, 2009, 2(1), p 20-32.

5. D.E. Wolfe, T.J. Eden, J.K. Potter, and A.P. Jaroh, Investigation and Characterization of Cr3C2-Based Wear-Resistant Coatings Applied by the Cold Spray Process, J. Therm. Spray Technol., 2006, 15(3), p 400-412.

6. H. Assadi, H. Kreye, F. Gärtner, and T. Klassen, Cold Spraying - A Materials Perspective, Acta Mater., Elsevier Ltd, 2016, 116, p 382-407.

7. D. Goldbaum, R.R. Chromik, N. Brodusch, and R. Gauvin, Microstructure and Mechanical Properties of Ti Cold-Spray Splats Determined by Electron Channeling Contrast Imaging and Nanoindentation Mapping, Microsc. Microanal., 2015, 21(3), p 570-581.

8. H. Assadi, F. Gärtner, T. Stoltenhoff, and H. Kreye, Bonding Mechanism in Cold Gas Spraying, Acta Mater., 2003, 51(15), p 4379-4394.

9. A. Moridi, S.M. Hassani-Gangaraj, M. Guagliano, and M. Dao, Cold Spray Coating: Review of Material Systems and Future Perspectives, Surf. Eng., 2014, 30(6), p 369-395.

10. V.K. Champagne, "The Cold Spray Materials Deposition Process Fundamentals and Applications," Woodhead Publishing Limited, 2007.

11. A. Papyrin, "Cold Spray Technology,” Elsevier, 2007.

12. P. Vo, E. Irissou, J.G. Legoux, and S. Yue, Mechanical and Microstructural Characterization of Cold-Sprayed Ti-6Al-4V after Heat Treatment, J. Therm. Spray Technol., 2013, 22(6), p 954-964.

13. T. Schmidt, F. Gärtner, H. Assadi, and H. Kreye, Development of a Generalized Parameter Window for Cold Spray Deposition, Acta Mater., 2006, 54(3), p 729-742.

14. D. Goldbaum, J.M. Shockley, R.R. Chromik, A. Rezaeian, S. Yue, J.G. Legoux, and E. Irissou, The Effect of Deposition Conditions on Adhesion Strength of Ti and Ti6A14V Cold Spray Splats, J. Therm. Spray Technol., 2012, 21(2), p 288-303. 
15. N.W. Khun, A.W.Y. Tan, K.J.W. Bi, and E. Liu, Effects of Working Gas on Wear and Corrosion Resistances of Cold Sprayed Ti-6Al-4V Coatings, Surf. Coat. Technol., 2016, 302, p 1-12.

16. H. Aydin, M. Alomair, W. Wong, and P. Vo, Cold Sprayability of Mixed Commercial Purity Ti Plus Ti6Al4V Metal Powders, J. Therm. Spray Technol., Springer US, 2017, 26(3), p 360-370.

17. W. Sun, A.W.Y. Tan, I. Marinescu, W.Q. Toh, and E. Liu, Adhesion, Tribological and Corrosion Properties of Cold-Sprayed CoCrMo and Ti6A14V Coatings on 6061-T651 Al Alloy, Surf. Coatings Technol., Elsevier B.V., 2017, 326, p 291-298.

18. A.W.Y. Tan, W. Sun, Y.P. Phang, M. Dai, I. Marinescu, Z. Dong, and E. Liu, Effects of Traverse Scanning Speed of Spray Nozzle on the Microstructure and Mechanical Properties of Cold-Sprayed Ti6A14V Coatings, J. Therm. Spray Technol., Springer US, 2017, 26(7), p 1484-1497.

19. V.S. Bhattiprolu, K.W. Johnson, O.C. Ozdemir, and G.A. Crawford, Influence of Feedstock Powder and Cold Spray Processing Parameters on Microstructure and Mechanical Properties of Ti-6Al-4V Cold Spray Depositions, Surf. Coatings Technol., Elsevier, 2018, 335, p 1-12.

20. D. MacDonald, R. Fernandez, F. Delloro, and B. Jodoin, Cold Spraying of Armstrong Process Titanium Powder for Additive Manufacturing, J. Therm. Spray Technol., 2017, 26(4), p 598-609.

21. M.V. Vidaller, A. List, F. Gaertner, T. Klassen, S. Dosta, and J.M. Guilemany, Single Impact Bonding of Cold Sprayed Ti-6Al-4V Powders on Different Substrates, J. Therm. Spray Technol., 2015, 24(4), p 644-658.

22. X.T. Luo, Y.K. Wei, Y. Wang, and C.J. Li, Microstructure and Mechanical Property of Ti and Ti6A14V Prepared by an in-Situ Shot Peening Assisted Cold Spraying, Mater. Des., Elsevier Ltd, 2015, 85, p 527-533.

23. K. Araci, D. Mangabhai, and K. Akhtar, "Production of Titanium by the Armstrong Process $®$," Titanium Powder Metallurgy: Science, Technology and Applications, Elsevier Inc., 2015.

24. A.M. Birt, V.K. Champagne, R.D. Sisson, and D. Apelian, Microstructural Analysis of Ti6Al-4V Powder for Cold Gas Dynamic Spray Applications, Adv. Powder Technol., The Society of Powder Technology Japan, 2015, 26(5), p 1335-1347.

25. Y. Zhang, N. Brodusch, S. Descartes, R.R. Chromik, and R. Gauvin, Microstructure Refinement of Cold-Sprayed Copper Investigated by Electron Channeling Contrast Imaging, Microsc. Microanal., 2014, 20, p 1499-1506.

26. W.C. Oliver and G.M. Pharr, "An Improved Technique for Determining Hardness and Elastic Modulus Using Load and Displacement Sensing Indentation Experiments," Journal of Materials Research, 1992, p 1564-1583.

27. D. Goldbaum, J. Ajaja, R.R. Chromik, W. Wong, S. Yue, E. Irissou, and J.G. Legoux, Mechanical Behavior of Ti Cold Spray Coatings Determined by a Multi-Scale Indentation 
Method, Mater. Sci. Eng. A, Elsevier B.V., 2011, 530(1), p 253-265.

28. A.M. Birt, V.K. Champagne, R.D. Sisson, and D. Apelian, Microstructural Analysis of Cold-Sprayed Ti-6Al-4V at the Micro- and Nano-Scale, J. Therm. Spray Technol., Springer US, 2015, 24(7), p 1277-1288.

29. J.I. Qazi, O.N. Senkov, J. Rahim, A. Genc, and F.H. (Sam) Froes, Phase Transformations in Ti-6Al-4V-xH Alloys, Metall. Mater. Trans. A, 2001, 32A(October), p 2453-2463.

30. B. Jodoin, L. Ajdelsztajn, E. Sansoucy, A. Zúñiga, P. Richer, and E.J. Lavernia, Effect of Particle Size, Morphology, and Hardness on Cold Gas Dynamic Sprayed Aluminum Alloy Coatings, Surf. Coat. Technol., 2006, 201, p 3422-3429.

31. W.D. Nix and H. Gao, Indentation Size Effects in Crystalline Materials : A Law for Strain Gradient Plasticity, J. Mech. Phys. Solids, 1998, 46(3), p 411-425.

32. I. Sen, S. Roy, and M.F.X. Wagner, Indentation Response and Structure-Property Correlation in a Bimodal Ti-6Al-4V Alloy, Adv. Eng. Mater., 2017, 1700298, p 1-12.

33. G.B. Viswanathan, E. Lee, D.M. Maher, S. Banerjee, and H.L. Fraser, Direct Observations and Analyses of Dislocation Substructures in the $\alpha$ Phase of an A/ $\beta$ Ti-Alloy Formed by Nanoindentation, Acta Mater., 2005, 53(19), p 5101-5115.

34. T.B. Britton, H. Liang, F.P.E. Dunne, and A.J. Wilkinson, The Effect of Crystal Orientation on the Indentation Response of Commercially Pure Titanium: Experiments and Simulations, Proc. R. Soc. London A Math. Phys. Eng. Sci., 2010, 466, p 695-719.

35. W. Sun, A. Wei, Y. Tan, N.W. Khun, I. Marinescu, and E. Liu, Effect of Substrate Surface Condition on Fatigue Behavior of Cold Sprayed Ti6Al4V Coatings, Surf. Coat. Technol., Elsevier B.V., 2017, 320, p 452-457.

36. C.M. Lewandowski, N. Co-investigator, and C.M. Lewandowski, Powder Metal Technologies and Applications, ASM Int. Mater. Park. OH, 2015, 7, p 2762.

37. W. Wong, P. Vo, E. Irissou, A.N. Ryabinin, J. Legoux, and S. Yue, Effect of Particle Morphology and Size Distribution on Cold-Sprayed Pure Titanium Coatings, J. Therm. Spray Technol., 2013, 22, p 1140-1153.

38. M. Winnicki, A. Małachowska, G. Dudzik, M. Rutkowska-Gorczyca, M. Marciniak, K. Abramski, A. Ambroziak, and L. Pawłowski, Numerical and Experimental Analysis of Copper Particles Velocity in Low-Pressure Cold Spraying Process, Surf. Coatings Technol., 2015, 268, p 230-240.

39. D. Lioma, N. Sacks, and I. Botef, Cold Gas Dynamic Spraying of WC-Ni Cemented Carbide Coatings, Int. J. Refract. Met. Hard Mater., Elsevier Ltd, 2015, 49, p 365-373.

40. S. Yin, E.J. Ekoi, T.L. Lupton, and P. Denis, Cold Spraying of WC-Co-Ni Coatings Using Porous WC-17Co Powders: Formation Mechanism, Microstructure Characterization and Tribological Performance, Mater. Des., Elsevier Ltd, 2017, 126, p 305-313.

41. P.H. Gao, Y.G. Li, C.J. Li, G.J. Yang, and C.X. Li, Influence of Powder Porous Structure on the Deposition Behavior of Cold-Sprayed WC-12Co Coatings, J. Therm. Spray Technol., 
2008, 17(5-6), p 742-749.

42. K.H. Kim, M. Watanabe, J. Kawakita, and S. Kuroda, Grain Refinement in a Single Titanium Powder Particle Impacted at High Velocity, Scr. Mater., 2008, 59(7), p 768-771.

43. D. Goldbaum, "Micromechanical Testing of Cold Sprayed Ti Splats and Coatings," McGill University, 2012. 